\title{
CHILDREN'S WITNESSING OF ADULT DOMESTIC VIOLENCE
}

Jeffrey L. Edleson

University of Minnesota

The author wishes to thank Susan Schechter and Andrea Bible for their helpful feedback provided on earlier versions of this manuscript.

Running head: Children's Experience of Domestic Violence

\begin{abstract}
Social service professionals are more frequently identifying children who witness adult domestic violence as victims of that abuse. This article expands common definitions of how children witness violence, and adult domestic violence in particular. Over 80 research papers were reviewed and a variety of behavioral, emotional, cognitive and physical functioning problems among children were found to be associated with exposure to domestic violence. Factors that appear to mediate the impact of witnessing violence, such as child gender, age, and time since last exposure to violence are identified. Concerns about research methodology are also raised.
\end{abstract}

\section{CHILDREN'S WITNESSING OF ADULT DOMESTIC VIOLENCE}

Many people have suggested that family violence - at least to the degree it is observed today - is a recent phenomenon. Yet violence between intimates has long been a part of family life. It has been described repeatedly in religious and historical documents across many centuries, dating as far back as the Roman Empire (Davidson, 1977; Dobash \& Dobash, 1979). Some have also argued that current levels of family violence reflect a break-down in the moral structure of the family (see Levine, 1986). This too is unlikely. Rather, as Gordon (1988) suggests, the "ebb-and-flow pattern of concern about family violence...suggests that its incidence has not changed as much as its visibility" (p. 2).

Children who witness violence between adults in their homes are only the most recent victims to become visible. These children have been called the "silent," "forgotten," and "unintended" victims of adult-to-adult domestic violence (Elbow, 1982; Groves et al., 1993; Rosenbaum \& O'Leary, 1981). Studies of archived case records from social service and governmental agencies provide ample evidence that violence has long occurred at levels similar to those measured today and that children are frequently present during violence incidents (Edleson, 1991; Gordon, 1988; Peterson, 1991; Pleck, 1987). 
An understanding of the current literature on how children witness violence and what developmental problems are associated with witnessing violence is an important foundation for program design and policy development. This article focuses on understanding how witnessing violence is defined and what we know about its effects on children.

\section{How Do Children Experience Domestic Violence?}

Witnessing a violent event is most commonly defined as being within visual range of the violence and seeing it occur. For example, witnesses are often portrayed as giving an "eyewitness account" of a crime. Pynoos and Eth's (1984) studies of children who witnessed the murder of a parent reinforce this definition. One example they offer is:

"Julie, a 4-year-old girl, was the only witness to her divorced mother's fatal stabbing. Several months earlier, at the time of the divorce, Julie's father had publicly threatened to kill his ex-wife...Although the father lacked an alibi for the night of the crime, there was no physical evidence linking him to the homicide...In describing the event, she (Julie) consistently placed her father at the scene, described significant portions of the central action, and recounted her father's efforts to clean up prior to leaving.... Only after the district attorney saw Julie stabbing a pillow, crying 'Daddy pushed mommy down,' did he become convinced that the father indeed was the murderer" (p. 100).

A mother in a different study describes her daughter's involvement in a violent event this way:

"As (my husband) came back in the house and went in the bedroom and got another bullet and loaded the gun again and started to raise the gun, I really think my daughter saved my life right then...I was holding her behind me, and she came out in front of me and put her arms in the doorway like this (demonstrating with her arms outstretched), so as he raised the gun it came right past her. And I reached out and I took her hands down, and her hands were so strong against that doorway. It was unbelievable the strength that was in her arms. I got her arms down, and I turned and grabbed her in my arms and ran out the door" (SyersMcNairy, 1990, pp. 105-106).

Pynoos and Eth (1984) suggest that "at the core of the trauma for the child witness to homicide is a continued intrusion into the child's mind of the central 
action when lethal physical harm was inflicted: the final blow with a fist, the plunge of a knife, or the blast of a shotgun" (p. 91).

Most children do not witness murders of a parent. Beatings that are not fatal but are nonetheless brutal are the types of events that we most commonly think of when children witness adult domestic violence. Peled (1993) provides dramatic testimony of one child witnessing such violence:

"I wouldn't say anything. I would just sit there. Watch it...I was just, felt like I was just sitting there, listening to a TV show or something...It's like you just sit there to watch it, like a tapestry, you sit there" (p. 122).

Being an "eyewitness" to a violent event is not, however, the only way that children describe their experiences. Many children describe very traumatic events that they have not visually observed, but rather that they have heard. One child described hearing fights this way:

"I really thought somebody got hurt. It sounded like it. And I almost started to cry. It felt really, I was thinking of calling, calling the cops or something because it was really getting, really big banging and stuff like that" (Peled, 1993, p. 125).

In their national curriculum for child protection workers, Ganley and Schechter (1996) highlight several additional ways that children experience adult domestic violence. These include hitting or threatening a child while in its mother's arms, taking the child hostage in order to force the mother's return to the home, using a child as a physical weapon against the victim, forcing the child to watch assaults against the mother or to participate in the abuse, and using the child as a spy or interrogating him or her about the mother's activities. Children are also frequently told by abusive fathers that their families would be together were it not for their mother's behavior, thus attempting to put pressure on the mother through the children to return to him or driving a wedge between the mother and her children.

In addition to seeing, hearing or being used in a direct event of violence many mothers and their children describe the aftermath of a violent event as having a traumatic effect on them. The aftermath can include a mother who is injured and in need of help, a father who alternates between physical violence and loving care, police intervention to remove a father from the home, or moving to a shelter for battered women. One mother, in her account to Syers-McNairy (1990), stated:

"It finally started to dawn on me that I was not the only person involved in it was when I left on the ambulance. They were so scared. And I 
thought, they don't really have a dad...And now they're not going to have a mom?" (p. 118).

Any definition of witnessing violence must include all of these various ways in which children experience a violent event. They may see the violence or be used as a part of it, but more often they may hear the violent event and experience its aftermath.

\section{How Often Do Children Witness Domestic Violence?}

\section{Incidence of Witnessing Violence}

Estimates vary on the number of children or teenagers who witness one parent abusing another. The two most widely cited statistics are those developed by Carlson (1984) and Straus (1992). Carlson estimated that "at least 3.3 million children yearly are at risk of exposure to parental violence" (p. 160). Her estimate is derived from earlier studies that found approximately 3 million American households experience at least one incident of serious violence each year (Straus, Gelles \& Steinmetz, 1980). Carlson adjusted this finding for the estimated number of households with children (55\%) and then multiplied by the average number of children per household (two). Carlson (1984) argues that her estimate is likely to be very low for several reasons. First, this number only includes exposure to serious violence, defined as violence likely to cause injury. Second, the Straus et al. study upon which Carlson's estimates are based excluded families with children under 3 years of age and families where the parents were separated or divorced but where violence may still be occurring. Finally, Carlson notes that violence may be somewhat higher in families with fewer economic resources which also - on average - tend to be larger families.

Straus (1992) has estimated that there may be as many as 10 million teenagers exposed to parental violence each year. His estimates resulted from a survey (see Straus \& Gelles, 1990) in which adults were asked "whether, during their teenage years, their father had hit their mother and how often" and vice versa (p. 98). He found that about one in eight or $12.6 \%$ of the sample recalled such an incident with $50 \%$ remembering their father hitting their mothers, $19 \%$ recalling the reverse, and $31 \%$ recalling both hitting the other. Adults recalled an average of 8.9 such violent incidents with a median of 4 events.

Straus goes on to estimate that "at least a third of American children have witnessed violence between their parents, and most have endured repeated instances" (p. 98). He bases this even larger estimate on the fact in his and Gelles' national survey $30 \%$ of parents who admitted the existence of adult domestic 
violence in their home reported that their children had witnessed at least one violent incident over the duration of the marriage. These findings are supported by Silvern et al. (1995) whose recent study of 550 college students found that 118 (41.1\%) of the 287 women and 85 (32.3\%) of the 263 men she studied had witnessed abuse by one parent against the other.

Regardless of the way these estimates of children's exposure are derived, it is clear that large numbers of children are exposed to violence between their parents. It is also likely that this exposure occurs more than once and may be present over the course of a child's development.

\section{Discrepancies in Reports}

There is a belief among some parents that their children are often shielded from exposure to the violence. Jaffe, Wolfe and Wilson (1990) report that many of the parents with whom they have worked believed their children did not "witness" an event because they were sleeping or playing outside. For example, one mother was quoted as follows:

"As far as Martin actually witnessing abuse toward me, a lot of the abuse toward me was either done when the kids were in bed or it was verbal abuse...I tried to keep as much of it away from the kids. I tried to be the role model of the perfect wife and mother as long as they were awake" (Peled, 1993, p. 86).

Jaffe et al. (1990) found, however, that children often provide detailed recollections of the very events they were not supposed to have witnessed. Reports by children and by adults of their childhood experiences suggest that parents may severely underestimate the degree to which their children are exposed to the violence. For example, O'Brien, John, Margolin and Erel (1994) found that one in four of the children in a community-based sample reported seeing violence used by one parent against another. Over a third (36\%) of these children reporting seeing violence used by fathers against mothers when at least one parent reported no violence occurred or that their children had not seen such events.

\section{Witnessing Violence}

Any discussion of problems associated with children witnessing domestic violence must acknowledge several areas of related research, including the research on: (1) witnessing discord in marital and other intimate adult relationships; (2) witnessing community violence; and (3) witnessing violence conveyed over popular media. These other ways that children witness conflict 
and violence are very closely related to witnessing domestic assaults. The research results reported in these areas are often difficult to separate from exposure to domestic violence and it is, therefore, important to acknowledge, however briefly, the important connection of these areas to the primary focus of this article which is on domestic violence.

\section{Relationship discord}

The violence that children witness in their homes is most often part of a larger context of marital or relationship discord. The research on children who experience discord between adults at home is reported in a literature that is mostly separate from that on witnessing violence. This separate literature reports on research studies that have examined the emotional health and behavior of children who live in families characterized by marital dissatisfaction, conflict, and divorce. Emery (1982) pointed out in an early review of this literature that most studies prior to the early 1980s focused on associating child problems with adults' reports of marital satisfaction. The problem with these earlier studies is that they neither directly measured children's exposure to relationship conflict nor did they identify exposure to domestic violence. Furthermore, in families where there was great relationship dissatisfaction among the adults, much of the dissatisfaction was hidden from the children according to parent reports.

More recently, Grych and Fincham (1990) reviewed studies that directly examined the relationship between marital conflict and children's adjustment. They argue that martial conflict is multi-dimensional, that it "may vary in frequency, intensity, content, and resolution and can be overt and covert" (Grych \& Fincham, 1990, p. 267), and that children's adjustment is also multidimensional with adaptiveness, emotional health, self-concept and achievement all being important factors of it.

Fifteen of the 19 studies (79\%) reviewed by Grych and Fincham found a statistical relationship between marital discord and child maladjustment. The findings were found in all types of families studied; those having gone through a separation or divorce, intact families seeking counseling, and intact families recruited from the community. The more a child was exposed to conflict the more likely he or she would experience child adjustment problems. This finding held true across all types of families studied, however, there is no indication that witnessing physical violence was measured in these studies; there is a likely mixing of non-violent and violent marital discord.

A wide range of child adjustment problems were found to be associated with exposure to marital conflict. These included externalized problems such as conduct disorder, delinquency, antisocial behavior and aggression as well as 
internalized problems such as depression, anxiety, and withdrawal (see Grych \& Fincham, 1990). Both boys and girls were affected as were children as young as two years old. Interestingly, children in families where conflict was hidden showed only insignificant differences from children living in families marked by marital satisfaction.

Long-term effects of divorce and parent-to-parent conflict on children's development have been studied by Wallerstein and her colleagues for several decades. Her review of the research (Wallerstein, 1991) points to frequent spillover effects of conflict between parents to the parent-child relationship. Over time, Wallerstein argues, these disrupted parent-child relationships are almost always detrimental to a child's development.

\section{Community violence}

Marital discord is not the only type of conflict that children may observe in their surroundings. A number of studies have suggested that some children witness significant violence in their communities. For example, Eth and Pynoos (1985) estimated that $10 \%$ to $20 \%$ of homicides in Los Angeles were witnessed by children. Jenkins, Bell and their colleagues (Jenkins \& Thompson, 1986; Bell \& Jenkins, 1993) have found in studies of Southside Chicago that over one-fourth of all children interviewed have either witnessed a shooting or a murder. A more recent study (Jenkins \& Bell, 1994) of a high violence neighborhood found that almost a half $(47 \%)$ of the youth interviewed had witnessed a stabbing and almost two-thirds (60.9\%) a shooting. Other studies in U.S. urban centers support the widespread witnessing of community violence among children and youth (see Osofsky, Wewers, Hann \& Fick, 1993; Schubiner, Scott \& Tzelepis, 1993; Fitzpatrick \& Boldizar, 1993; Richters \& Marinez, 1993).

Some effects of witnessing community violence have been identified as acting out behavior (Eth \& Pynoos, 1985), higher levels of stress (Fitzpatrick \& Boldizar, 1993; Lorion \& Saltzman, 1990; Osofsky et al., 1993), more depression (Freeman, Mokros \& Poznanski, 1993; Martinez \& Richters, 1993) and belligerence (Green et al., 1991). DuRant and his colleagues (DuRant et al., 1994a; DuRant, Pendergrast \& Cadenhead, 1994b) have shown that adolescents' exposure to violence and their own victimization are associated with subsequent use of aggressive and violent behaviors. They found that a child's clearer sense of purpose in life and lower degrees of reported depression tempered the negative influences of being exposed to violence. O'Keefe's (in press) study of 935 high school students also found that exposure to community and school violence were significant predictors of boys' aggressive and acting-out behavior while only exposure to school violence significantly predicted girls use of aggression. 


\section{Violence in the media}

The third and final area of related research is also the most studied and discussed area; it is children's exposure to violence in the media. Perhaps the most comprehensive review of the effects viewing violent media have on children and adults is found in Paik and Comstock's (1994) analysis of 217 studies on individuals' observation of media violence. They found a consistent "positive and significant correlation between television violence and aggressive behavior" (p. 516). These associations remained strong across a variety of types of studies, from experiments to surveys.

Paik and Comstock's specific results included the findings that males showed more problems associated with exposure to television violence than did females, but also showed both males and females to be significantly affected by viewing violence on television. The youngest viewers - nursery school aged children showed the greatest effect but were the least likely to go on to use violence against others. Throughout all age groups, however, the effects of viewing violence on subsequent use of aggressive behaviors remained high. Finally, Paik and Comstock found that viewing television violence appeared to have the greatest influence on subsequent use of aggressive play, intentions to do play aggressively, use of verbal aggression, and use of "non-criminal" violence against others. Overall, the results of these studies indicated that children's observation of television and other media violence were likely to be influential factors in their development of subsequent aggressive and illegal behaviors.

As attention is now turned to examining childhood problems associated with witnessing adult domestic violence, we should keep this larger context of a child's life in mind. Children are viewing multiple forms of conflict and violence, and all of these forms appear to affect the child's emotional health and behavioral development.

\section{Witnessing Domestic Violence}

There is a growing body of literature that has examined both the short and longterm problems associated with children's witnessing of domestic violence. Over 80 studies that report associations between witnessing domestic violence and child development problems were found in the literature. Several authors have produced extensive reviews of this literature (see Fantuzzo \& Lindquist, 1989; Holtzworth-Munroe, Smutzler \& Sandin, in press; Jaffe \& Sudermann, 1995; Kashani, Daniel, Dandoy \& Holcomb, 1992; Kolbo, Blakely \& Engleman, 1996; Peled \& Davis, 1995). This growing literature reveals some clear trends in the types of child development problems associated with exposure to adult domestic violence. The studies produced to date also, however, display some significant 
weaknesses and gaps that make strong conclusions concerning the effects of witnessing domestic violence premature. The sections below present a selective overview of these findings, weaknesses in current studies, and gaps yet to be studied.

\section{Children's Problems Associated with Witnessing Violence}

Reviewed studies report a series of childhood problems statistically associated with a child's witnessing of domestic violence. These problems can be grouped into the three main categories examining effects of recent witnessing - (1) behavioral and emotional functioning; (2) cognitive functioning and attitudes; (3) physical functioning - and a fourth category that examined long-term effects. Each of these four categories are reviewed in more detail below.

Behavioral and emotional problems. The area in which there is probably the greatest amount of information on problems associated with witnessing adult domestic violence is in the area of children's behavioral and emotional functioning. Generally, studies using the Child Behavior Checklist (CBCL; Achenbach \& Edelbrock, 1983) and similar measures have found child witnesses of domestic violence to exhibit more aggressive and antisocial (often called "externalized" behaviors) as well as fearful and inhibited behaviors ( "internalized" behaviors) (Christopherpoulos et al., 1987; Davis \& Carlson, 1987; Fantuzzo et al., 1991; Holden \& Ritchie, 1991; Hughes, 1988; Hughes, Parkinson \& Vargo, 1989; Jaffe et al., 1986; Jouriles, Murphy \& O'Leary, 1989; Kerouac, Taggart, Lescop \& Fortin, 1986; Stagg, Wills \& Howell, 1989; Wolfe et al., 1985), and to show lower social competence than other children (Davis \& Carlson, 1987; Fantuzzo et al., 1991; Stagg, Wills \& Howell, 1989; Wolfe et al., 1985, 1986). Children who witnessed violence were also found to show more anxiety, selfesteem, depression, anger, and temperament problems than children who did not witness violence at home (Christopherpoulos et al., 1987; Forsstrom-Cohn \& Rosenbaum, 1985; Holden \& Ritchie, 1991; Hughes, 1988; Martin et al., 1987; Westra \& Martin, 1981). Children from homes where their mothers were being abused have shown less skill in understanding how others feel and examining situations from others' perspectives when compared to children from nonviolent households (Hinchey \& Gavelek; 1982).

Overall, these studies indicate a consistent finding across various samples and differing methodologies that child witnesses of domestic violence exhibit a host of behavioral and emotional problems. A few studies have reported finding no differences on some of these measures, but these same studies reported significant differences on other measures ( for example, Christopherpoulos et al., 1987; Wolfe et al., 1986). 
Another aspect of the effects on children is their own use of violence. Social learning theory would suggest that children who witness violence may also learn to use it. Several researchers have attempted to look at this link between exposure to domestic violence and subsequent use of it. Some support for this hypothesis has been found. For example, Carlson (1990) found that adolescent males who witnessed spouse abuse were significantly more likely to use violence than non-witnesses. There were no significant differences found for females in her study.

Cognitive functioning and attitudes. A number of studies have measured the association between cognitive development problems and witnessing domestic violence. Children resident in shelters were found to show significantly lower verbal and quantitative skills when compared to a national sample (Westra \& Martin, 1991). Children's exposure to adult domestic violence was also significantly associated with greater immaturity and inadequacy among both boys and girls (Jouriles, Murphy \& O’Leary, 1989).

One of the most direct consequences of witnessing violence may be the attitudes a child develops concerning the use of violence and conflict resolution. Jaffe, Wilson and Wolfe (1986) suggest that children's exposure to adult domestic violence may generate attitudes justifying their own use of violence. Spaccarelli, Coatsworth and Bowden's (1995) findings support this association by showing that adolescent boys incarcerated for violent crimes who had been exposed to family violence believed more than others that "acting aggressively enhances one's reputation or self-image" (p. 173). Believing that aggression would enhance their self-image significantly predicted violent offending.

Boys and girls appear to differ in what they learn from these experiences. Carlson (1991) found that adolescent boys who witnessed domestic violence were significantly more likely to approve of violence than were girls who had also witnessed it.

Physical functioning. Few studies have reported on children's physical conditions. Larsson and Andersson (1988) found that Swedish children living in families where adult domestic violence was occurring had "almost twice as many admissions to the hospital (than controls). The majority had been hospitalized during their pre-school age" (p. 166). Children in this study who were exposed to domestic violence also recorded psychosomatic complaints more often than children in control groups. Kerouac, et al. (1986) found that children residing in a Montreal shelter were almost twice as often absent from school for health problems when compared to government data on the general populations of Canadian and American children. 
Long-term effects on development. Most studies reviewed to this point have examined child problems associated with recent witnessing of domestic violence. A number of studies have mentioned much longer term effects reported retrospectively by adults or indicated in archival records. For example, Silvern et al. (1995) found that witnessing violence as a child was associated with adult reports of depression, trauma-related symptoms and low self-esteem among women and trauma-related symptoms alone among men. These effects appeared to be independent of the effects of parental alcohol abuse and divorce. In the same vein, Henning et al. (1996) found that adult women who had witnessed domestic violence as a child showed greater distress and lower social adjustment than non-witnesses. These findings persisted even after accounting for the effects of witnessing parental verbal conflict, being abused as a child, and level of reported parental caring.

There is also some support for the hypothesis that children from violent families of origin carry violent and violence-tolerant roles to their adult intimate relationships (Cappell \& Heiner, 1990; Rosenbaum \& O'Leary, 1981; Widom, 1989). For example, Rosenbaum and O'Leary (1981) reported that the male batterers in their study were much more likely than others to have grown up in homes where adult domestic violence was occurring. A similar finding is also reported in a study by Barnett, Butler and Ryska (1987). Likewise, Suh and Abel (1990) found that batterers who were abused as a child were more likely to abuse their own children.

Finally, several authors have reported strong associations between childhood victimization and later adult violent and criminal behavior (Rivera \& Widom, 1990; Widom, 1989). Violent adolescents were shown to have been seriously physically abused by a parent and to have witnessed weapons violations between adults in their homes significantly more often than were others (Spaccarelli, et al., 1995). These two variables, independently and in combination, were significantly associated with an adolescent's use of violence.

\section{Factors Influencing the Degree of Problems Associated with Witnessing Violence}

Several factors appear to mediate the degree to which a child is affected by witnessing violence. As will be seen below, a number of these factors also seem to interact with each other creating unique outcomes for different children.

Abused and witnessing children. Hughes, Parkinson and Vargo (1989) have suggested that both witnessing abuse and also being abused is a "double whammy" for children. Their study compared children who were both abused and had witnessed violence to children who had only witnessed violence and to 
others who had been exposed to neither type of violence. They found that children who were both abused and witnesses exhibited the most problem behaviors; the witness-only group showed moderate problem symptoms and the comparison group the least. This same pattern appears in series of other studies (Carlson, 1991; Davis \& Carlson, 1987; Hughes, 1988; Miller, Handal, Gilner \& Cross, 1991; O'Keefe, 1994a; Stagg et al., 1989; and Sternberg et al., 1993).

Children seem to agree. For example, in one study children indicated that the experience of being abused or both abused and a witness is more negative from their perspective than witnessing adult domestic violence alone (McClosky, Figueredo \& Koss, 1995).

It appears, based on the above review that the combination of being abused and witnessing violence appears to be associated with more serious problems for children than witnessing violence alone. Silvern, et al. (1995) found, however, that after accounting for the effects of being abused, adult reports of their childhood witnessing of adult domestic violence still accounted for a significant degree of their problems as children. Silvern and her colleagues suggest that witnessing domestic violence may result in traumatic effects on children that are distinct from the effects of child abuse.

Child characteristics. The most consistent findings in the literature point to different factors for boys and girls that are associated with witnessing violence. In general, studies have shown boys to exhibit more frequent problems and ones that are categorized as externalized such as hostility and aggression and with girls showing evidence of more internalized problems such as depression and somatic complaints (Carlson, 1990, 1991; Forsstrom-Cohen \& Rosenbaum, 1985; Hilberman \& Munson, 1977; Hinchey \& Gavelek, 1982; Holden \& Ritchie, 1991; Jaffe et al., 1986; Jouriles, Murphy \& O'Leary, 1989; Porter \& O'Leary, 1980; Stagg et al., 1989; Westra \& Martin, 1981). There are some findings that dissent from this general trend by showing that girls, especially as they get older, also exhibit more aggressive behaviors (for example, Christopoulous et al., 1987; Spaccarelli, Sandler \& Roosa, 1994; Davis \& Carlson, 1987).

Children of different ages also appear to exhibit differing responses associated with witnessing violence. Children in preschool showed lower than expected self-concept scores while older, school-aged children showed gender differences on aggression, with boys being more aggressive than girls (Hughes \& Barad, 1983). This was especially true in the group of children who were both witnesses and themselves victims of abuse.

Few studies have found differences based on race and ethnicity. O'Keefe's (1994b) study of white, Latino, and African-American families of battered women found that all the children were viewed by their mothers as having 
serious emotional and behavioral problems. The only difference found between the groups was on social competence; African-American mothers rated their children more competent when compared to other mothers' ratings of their own children.

Time since violent event. Consistent with the marital discord literature, the longer the period of time since exposure to a violent event the fewer affects a child experiences. For example, Wolfe, Zak, Wilson and Jaffe (1986) found more social problems among children residing in shelters than among children who had at one time in the past been resident in a shelter. The effect of the immediate turmoil may temporarily escalate child problems as observed in a shelter setting.

Parent-child relationship factors. A number of authors have discussed a child's relationship to adult males in the home as a key factor. Peled (1996) suggests that children's relationships with their battering fathers were confusing, with children expressing both affection for their fathers and resentment, pain and disappointment over his violent behavior.

Children's relationships to their mothers have also been identified as a key factor in how children are affected by witnessing domestic violence. Some have conjectured that a mother's mental health would negatively affect a child's experience of violence but the data are conflicting. Wolfe, et al. (1985) found that maternal stress statistically accounted for a large amount of child behavior problems. Another study of child witnesses of violence, however, found that mothers' mental health did not affect a child's response to violence in the home (McClosky et al.,1995).

Family support and children's perceptions of their parental relationships have also been identified as key parent-child variables. For example, Durant et al. (1994a) found home environments to be important among the 225 urban black adolescents they studied. Adolescents exposed to community and domestic violence appeared to cope better if they lived in more stable and socially connected households.

\section{Coping strategies and child resilience}

To this point, little has been said about how children cope with exposure to domestic violence. A number of authors have pointed to the mechanisms that children use to cope with violence exposure. For example, Kerouac, et al. (1986) report that children's behavior during a violent event included crying, shouting at their mother or pleading in her favor, remaining silent, leaving the room, playing a part in the violent event, seeking attention through noisy behavior and restlessness, or choosing one parent as a target. After the violent event, children 
sought security and comfort from their mother or adopted a parent role to comfort her. O'Brien, Margolin, John and Krueger (1991) found that the boys in their study who witnessed physical aggression between parents were less able to deal with simulated family interactions, more likely to report that they would actively intervene in family conflicts, more aroused by simulated conflicts and less likely to criticize people in the simulated conflicts than were boys from families where no violence was reported. Spaccarelli et al. (1995) also reported that adolescent boys who had experienced serious physical violence and been exposed to interadult weapons use at home were significantly more likely than others to use aggressive control as a coping strategy.

On the other hand, Jaffe et al. (1990) point out that while their research on children resident in shelters has shown large numbers of them to exhibit negative effects associated with exposure to violence, there are many other children in their studies who show few negative symptoms and some even show higher social competence than comparison children. Indeed, several authors have suggested that specific coping strategies may lessen the effects of violence on children. Sternberg et al. (1993) conclude that "perhaps the experience of observing spouse abuse affects children by a less direct route than physical abuse, with cognitive mechanisms playing a greater role in shaping the effects of observing violence" (p. 50).

What are these coping strategies that some children develop to help them better survive exposure to domestic violence? Peled (1993) suggests that child witnesses of domestic violence use what Folkman and Lazarus (1980) call both "emotionfocused" and "problem-focused" coping strategies. Emotion-focused strategies are those that a child uses to control his or her own emotional response to witnessing violent events. Peled (1993) found that the children mostly applied this type of strategy including "wishing the violence away at the time of a fight, reframing and minimizing the violence, forgiving father, and refusing to talk about the violence" (Peled, 1993, p. 220). Problem-focused strategies that children commonly used were characterized by actions aimed at changing events and were used less often by children in Peled's (1993) study. These included children physically distancing themselves from or inserting themselves into the violent event.

Holtzworth-Munroe, Smutlzer and Sandin's (in press) review of the literature also suggests that child problems resulting from witnessing domestic violence may be reframed as active coping mechanisms. In their view, children's problems are ways to express negative emotions, receive reassurances and divert attention from marital problems in the home. There is, however, very little specific research to date that focuses on how child witnesses to adult domestic 
violence successfully cope with their home environments and what, if anything can be done to establish and enhance such strategies.

\section{Research methodologies}

Interpreting this literature raises several problems based on the research methodologies applied. These include problems with definitions, samples, sources of information, measures, and research designs. Each is reviewed below. While together these flaws raise serious questions about this body of literature, they should not cause us to dismiss findings that are consistently replicated across different studies using different methods and samples. They should, however, raise caution.

Definitions. A significant problem in this body of literature is that many researchers have failed to differentiate abused children from those who are not themselves abused but who do witness domestic violence. Often, a child who has entered a shelter with a battered woman is assumed to have witnessed the violence yet few researchers have made efforts to measure the degree of exposure to domestic violence that a child has experienced. In addition, a recent review revealed that among $30 \%$ to $60 \%$ of families where either child physical abuse or woman battering were identified, the other form of violence was also present (Edleson, 1997). In an extreme example, Kolbo (1996) notes that of the 60 child witnesses he studied at a non-shelter domestic violence program all but two were also targets of violence. Some authors do not even identify the degree to which the children studied are both abused and witnessing domestic violence. Rather, they sometimes present their data as representative of children who only witness violence. As Silvern et al. (1995) have stated, "the relationship between reported partner and child abuse should warn that research could be flawed if it is assumed that shelter samples of children have been exposed solely to partner abuse" (p. 195).

Samples. Another issue in this literature is that most studies draw on samples of children and their mothers who are located in shelters for battered women. While this research generates very important information for shelter-based programs, residing in shelters may be a very stressful point in a child's life and not representative of his or her mental health in the long run. Not only have shelter-resident children most likely witnessed a violent event but they have also been removed from the familiar surroundings of their homes, neighborhoods and often their schools.

Sources of reports. Who reports the child's problems in a study may also skew the information we receive. Almost all of the studies reported above relied on mothers' reports of their children's problems. As pointed out earlier, O'Brien, et 
al.(1994) have shown that many parents report their children are unaware of violence between the adults when the children, in fact, report awareness of it. Studies that rely on the reports of only parents to define witnessing may incorrectly classify significant numbers of children as non-witnesses. Studies have also shown that in reports of other forms of maltreatment there are discrepancies between child, parent, clinician and agency ratings of problems. For example, Sternberg and Dawud-Noursi (in press) have found that child witnesses of violence and their parents differ significantly on the problems they report to researchers.

Measures. The over-reliance on a single reporter is a theme that is carried through to the measures used in these studies. The reason "internalized" or "externalized" behavior problems are so frequently mentioned in this literature is a direct result of the repeated use of the Child Behavior Checklist as mentioned earlier. Very few investigators have ventured beyond the use of this measure or a few others such and there is not currently a standardized measure developed that addresses the unique problems experienced by children who witness violence at home. Variables not yet regularly measured include a child's perceived safety, the disruption of a child's social support network among extended family members, school personnel and friends, the safety and effect of visitation arrangements, and the effect of changed economic factors on the child's development.

Design. A final weakness in this area of study is that most studies are correlational. As Holtzworth-Munroe, et al. (in press) point out, these studies only show associations between being a witness and some other variable such as a behavior problem. We generally speak of the effects of witnessing violence on children's development. In reality, however, these studies reveal only an association between the variables without predicting that one variable caused the other to occur or vice versa. Many people make the assumption that finding an association is the same as finding that a particular event such as witnessing domestic violence caused a child's problems.

\section{Conclusion}

Children experience adult domestic violence in many ways. This article has attempted to expand common definitions of how children witness adult domestic violence by showing how children not only see violence but also hear it occurring, are used as part of it, and experience the its aftermath. The article has also attempted to convey a sense of the estimated number of American children who witness adult domestic violence. 
Primary attention has been given to reviewing the complex influences on children's development that are associated with exposure to adult domestic violence. The complexity involves not just problems associated with exposure to violence but also various mediating factors and coping strategies that children utilize. The current literature offers only glimpses of children's resilience and the factors in their environments that lessen or heighten the impact of the violent events swirling around them. It is these factors about which we know so little that may lead us to designing more effective interventions to minimize the impact of violence on children.

The complexity of this issue is also emphasized by the multiple related forms of exposure to conflict and violence that children experience; specifically exposure to marital discord, community and media violence. The fragmentation of research studies on these issues leaves us with little knowledge of the combined impact on children of multiple forms of witnessing violence and conflict. We can only hypothesize that the cumulative effects may be devastating for some children.

Finally, this review also points to the many areas where we know little about how exposure to adult domestic violence affects children's lives. The over dependence on adult reports, on reports of children in immediate crisis, and on standardized measures that miss many important factors in a child's life leave many questions unanswered. While a number of excellent studies are evident among those reviewed, a great deal of work lies ahead in the development of a more sophisticated understanding of how children are affected by their exposure to adult domestic violence.

\section{References}

Achenbach, T.M. \& Edelbrock, C. (1983). Manual for the Child Behavior Checklist and Revised Child Behavior Profile. Burlington, VT: University of Vermont Department of Psychiatry.

Barnett, O., Butler, K.E. \& Ryska, T.A. (1987). Abuse of batterers and their exposure to violence during childhood. Paper presented at the Third National Conference of Domestic Violence Researchers, July 1987, Durham, New Hampshire.

Bell, C.C. \& Jenkins, E.J. (1993). Community violence and children on Chicago's Southside. Psychiatry, 56, 46-54. 
Cappell, C., \& Heiner, R. B. (1990). The intergenerational transmission of family aggression. Journal of Family Violence, 5, 135-152.

Carlson, B. E. (1984). Children's observations of interparental violence. In A. R. Roberts (Ed.), Battered women and their families, (pp. 147-167), New York: Springer.

Carlson, B.E. (1990). Adolescent observers of marital violence. Journal of Family Violence, 5, 285-299.

Carlson, B.E. (1991). Outcomes of physical abuse and observation of marital violence among adolescents in placement. Journal of Interpersonal Violence, 6, 526-534.

Christopherpoulos, C., Cohn, A. D., Shaw, D. S., Joyce, S., Sullivan-Hanson, J., Kraft, S. P., \& Emery, R. E. (1987). Children of abused women: I. Adjustment at time of shelter residence. Journal of Marriage and the Family, 49, 611-619.

Davidson, T. (1977). Wifebeating: A recurring phenomenon throughout history. In Maria Roy (Ed.) Battered women (pp. 2-23). New York: Van Nostrand Reinhold.

Davis, L.V. \& Carlson, B.E. (1987). Observation of spouse abuse: What happens to the children? Journal of Interpersonal Violence, 2, 278-291.

Dobash, R.E. \& Dobash, R.P. (1979). Violence against wives. New York: Free Press.

DuRant, R.H., Cadenhead, C, Pendergrast, R.A., Slavens, G. \& Linder, C.W. (1994a). Factors associated with the use of violence among urban Black adolescents. American Journal of Public Health, 84, 612-617.

DuRant, R.H., Pendergrast, R.A., and Cadenhead, C. (1994b). Exposure to violence and victimization and fighting behavior. Journal of Adolescent Health, $15,311-318$.

Edleson, J.L. (1991). Social workers' intervention in woman abuse: 1907 to 1945. Social Service Review, 65, 304-313.

Edleson, J.L. (1997). The overlap between child maltreatment and woman battering. Manuscript submitted for publication. St. Paul, MN: University of Minnesota School of Social Work. 
Elbow, M. (1982). Children of violent marriages: The forgotten victims. Social Casework, 63, 465-471.

Eth, S. \& Pynoos, R.S. (1985). Developmental perspective on psychic trauma in childhood. In C.R. Figley (Ed.), Trauma and its wake (pp. 36-52). New York: Brunner/Mazel.

Emery, R.E. (1982). Interparental confllict and the children of discord and divorce. Psychological Bulletin, 92, 310-330.

Fantuzzo, J.W. \& Lindquist, C.U. (1989). The effects of observing conjugal violence on children: A review and analysis of research methodology. Journal of Family Violence, 4, 77-94.

Fantuzzo, J.W., DePaola, L.M., Lambert, L., Martino, T., Anderson, G. \& Sutton, S. (1991). Effects of interparental violence on the psychological adjustment and competencies of young children. Journal of Consulting and Clinical Psychology, $59,258-265$.

Fitzpatrick, K.M. \& Boldizar, J.P. (1993). The prevalence and consequences of exposure to violence among African-American youth. Journal of the American Academy of Child and Adolescent Psychiatry, 32, 424-430.

Folkman, S. \& Lazarus, R.S. (1980). An analysis of coping in a middle-aged community sample. Journal of Health and Social Behavior, 21, 219-239.

Forsstrom-Cohn, B., \& Rosenbaum, A. (1985). The effects of parental marital violence on young adults: An exploratory investigation. Journal of Marriage and the Family, 47, 467-472.

Freeman, L.N., Mokros, H. \& Poznanski, E.O. (1993). Violent events reported by normal urban school-aged children: Characteristics and depression correlates. Journal of the American Academy of Child and Adolescent Psychiatry, 32, 419423.

Ganley, A.L. \& Schechter, S. (1996). Domestic violence: A national curriculum for children's protective services. San Francisco, CA: Family Violence Prevention Fund.

Gordon, L. (1988). Heroes of their own lives - The politics and history of family violence - Boston 1880-1960. New York: Viking Penguin. 
Groves, B.M., Zukerman, B., Marans, S. \& Cohen, D.J. (1993). Silent victims. Journal of the American Medical Association, 269, 262-264.

Grych, J.H. \& Fincham, F.D. (1990). Marital conflict and children's adjustment: A cognitive-contextual framework. Psychological Bulletin, 108, 267-290.

Henning, K., Leitenberg, H., Coffey, P., Turner, T. \& Bennett, R.T. (1996). Longterm psychological and social impact of witnessing physical conflict between parents. Journal of Interpersonal Violence, 11, 35-51.

Hilberman, E. \& Munson, K. (1977-78). Sixty battered women. Victimology, 2, 460-470.

Hinchey, F.S. \& Gavelek, J.R. (1982). Empathic responding in children of battered women. Child Abuse and Neglect, 6, 395-401.

Holden, G. W., \& Ritchie, K. L. (1991). Linking extreme marital discord, child rearing, and child behavior problems: Evidence from battered women. Child Development, 62, 311-327.

Holtzworth-Munroe, A., Smutzler, N. \& Sandin, B. (in press). A brief review of the research on husband violence. Part II: The psychological effects of husband violence on battered women and their children. Aggression and Violent Behavior.

Hughes, H. M. (1988). Psychological and behavioral correlates of family violence in child witness and victims. American Journal of Orthopsychiatry, 58, 77-90.

Hughes, H.M. \& Barad, S.J. (1983). Psychological functioning of children in a battered women's shelter: A preliminary investigation. American Journal of Orthopsychiatry, 53, 525-531.

Hughes, H.M., Parkinson, D. \& Vargo, M. (1989). Witnessing spouse abuse and experiencing physical abuse: A "double whammy"? Journal of Family Violence, 4, 197-209.

Jaffe, P.G. \& Suderman, M. (1995). Child witnesses of woman abuse: Research and community responses. In S.M. Stith \& M.A. Straus (Eds.), Understanding partner violence (pp. 213-222). Minneapolis, MN: National Council on Family Relations. 
Jaffe, P., Wilson, S., \& Wolfe, D. (1986). Promoting changes in attitudes and understanding of conflict among child witnesses of family violence. Canadian Journal of Behavioral Science, 18, 356 - 380.

Jaffe, P.G., Wolfe, D.A. \& Wilson, S.K. (1990). Children of battered women. Newbury Park, CA: Sage.

Jenkins, E.J. \& Bell, C.C. (1994). Violence exposure, psychological distress, and high risk behaviors among inner-city high school students. In S. Friedman (Ed.) Anxiety disorders in African-Americans (pp. 76-88). New York: Springer.

Jenkins, E.J. \& Thompson, B. (1986). Children talk about violence: Preliminary findings from a survey of black elementary school children. Paper presented at the Nineteenth Annual Convention of the Association of Black Psychologists, Oakland, CA.

Jouriles, E.N., Murphy, C.M. \& O'Leary, K.D. (1989). Interspousal aggression, marital discord, and child problems. Journal of Consulting and Clinical Psychology, 57, 453-455.

Kashani, J.H., Daniel, A.E., Dandoy, A.C. \& Holcomb, W.R. (1992). Family violence: Impact on children. Journal of the American Academy of Child and Adolescent Psychiatry, 31, 181-189.

Kerouac, S., Taggart, M.E., Lescop, J. \& Fortin, M.F. (1986). Dimensions of health in violent families. Health Care for Women International, 7, 413-426.

Kolbo, J.R. (1996). Risk and resilience among children exposed to family violence. Violence \& Victims, 11, 113-128.

Kolbo, J. R., Blakely, E., \& Engleman, D. (1996). Children who witness domestic violence: A review of empirical literature. Journal of Interpersonal Violence, 11, 281-293.

Larson, G. \& Andersson, M. (1988). Violence in the family: Morbidity and medical consumption. Scandinavian Journal of Social Medicine, 16, 161-166.

Levine, E.M. (1986). Sociocultural causes of family violence: A theoretical comment. Journal of Family Violence, 1, 3-12.

Lorion, R.P. \& Saltzman, W. (1990, November). Children's exposure to community violence: Following a path from concern to research to action. 
Paper presented at the National Conference on Community Violence and Children's Development, Bethesda, MD.

Martin, M.J., Schumm, W.R., Bugaighis, M.A., Jurich, A.P. \& Bollman, S.R. (1987). Family violence and adolescents' perceptions of outcomes of family conflict. Journal of Marriage and the Family, 49, 165-171.

Martinez, P. \& Richters, J.E. (1993). The NIMH Community Violence Project: II. Children's distress symptoms associated with violence exposure. Psychiatry, 56, 22-35.

McClosky, L.A., Figueredo, A.J. \& Koss, M.P. (1995). The effects of systemic family violence on children's mental health. Child Development, 66, 1239-1261.

Miller, T.R., Handal, P.J., Gilner, F.H. \& Cross, J.F. (1991). The relationship of abuse and witnessing violence on the Child Abuse Potential Inventory with Black adolescents. Journal of Family Violence, 6, 351-363.

O'Brien, M., John, R.S., Margolin, G. \& Erel, O. (1994). Reliability and diagnostic efficacy of parents' reports regarding children's exposure to marital aggression. Violence and Victims, 9, 45-62.

O'Brien, M., Margolin, G., John, R.S. \& Krueger, L. (1991). Mothers' and sons' cognitive and emotional reactions to simulated marital and family conflict. Journal of Consulting and Clinical Psychology, 59, 692-703.

O'Keefe, M. (1994a). Linking marital violence, mother-child/father-child aggression, and child behavior problems. Journal of Family Violence, 9, 63-78.

O'Keefe, M. (1994b). Racial/ethnic differences among battered women and their children. Journal of Child and Family Studies, 3, 283-305.

O'Keefe, M. (in press). Adolescents' exposure to community and school violence: Prevalence and behavioral correlates. Journal of Adolescent Health.

Osofsky, J.D., Wewers, S., Hann, D.M. \& Fick, A.C. (1993). Chronic community violence: What is happening to our children? Psychiatry, 56, 36-45.

Paik, H. \& Comstock, G. (1994). The effects of television violence on antisocial behavior: A meta-analysis. Communication Research, 21, 516-546. 
Peled, E. (1993). The experience of living with violence for preadolescent witnesses of woman abuse. Unpublished doctoral dissertation, University of Minnesota, Minneapolis.

Peled, E. (1996). The experience of living with violence for preadolescent witnesses of woman abuse. Manuscript submitted for publication. Tel Aviv, Israel: Bob Shappell School of Social Work, Tel Aviv University.

Peled, E. \& Davis, D. (1995). Groupwork with children of battered women. Thousand Oaks, CA: Sage.

Peterson, D. (1991). Physically violent husbands of the 1890s and their resources. Journal of Family Violence, 6, 1-15.

Pleck, E.H. (1987). Domestic tyranny: The making of social policy against family violence from Colonial times to present. New York: Oxford University Press.

Porter, B. \& O'Leary, D.K. (1980). Marital discord and childhood behavior problems. Journal of Abnormal Child Psychology, 8, 287-295.

Pynoos, R.S. \& Eth, S. (1984). The child as a witness to homicide. Journal of Social Issues, 40, 87-108.

Richters, J.E. \& Martinez, P. (1993). The NIMH Community Violence Project: I. Children as victims of and witnesses to violence. Psychiatry, 56, 7-21.

Rivera, B. \& Widom, C. (1990). Childhood victimization and violent offending. Violence \& Victims, 5, 19-35.

Rosenbaum, A., \& O'Leary, D. K. (1981). Children: The unintended victims of marital violence. American Journal of Orthopsychiatry, 51, 692-699.

Schubiner, H., Scott, R. \& Tzelepis, A. (1993). Exposure to violence among innercity youth. Journal of Adolescent Health, 14, 214-219.

Silvern, L., Karyl, J., Waelde, L., Hodges, W.F., Starek, J., Heidt, E. \& Min, Kyung (1995). Retrospective reports of parental partner abuse: Relationships to depression, trauma symptoms and self-esteem among college students. Journal of Family Violence, 10, 177-202.

Silvern, L., Karyl, J., Waelde, L., Hodges, W.F., Starek, J., Heidt, E. \& Min, Kyung (1995). Retrospective reports of parental partner abuse: Relationships to 
depression, trauma symptoms and self-esteem among college students. Journal of Family Violence, 10, 177-202.

Spaccarelli, S., Sandler, I.N. \& Roosa, M. (1994). History of spouse violence against mother: Correlated risks and unique effects in child mental health. Journal of Family Violence, 9, 79-98.

Spaccarelli, S., Coatsworth, J.D. \& Bowden, B.S. (1995). Exposure to serious family violence among incarcerated boys: Its association with violent offending and potential mediating variables. Violence and Victims, 10, 163-182.

Stagg, V., Wills, G.D. \& Howell, M. (1989). Psychopathology in early childhood witnesses of family violence. Topics in Early Childhood Special Education, 9, 7387.

Sternberg, K.J., Lamb, M.E., Greenbaum, C., Cicchetti, D., Dawud, S., Cortes, R.M., Krispin, O. \& Lorey, F. (1993). Effects of domestic violence on children's behavior problems and depression. Developmental Psychology, 29, 44-52.

Sternberg, K.J. \& Dawud-Noursi, S. (in press). Effects of domestic violence on children's behavior problems: Multiple perspectives. In Tessier, R. \& Tarbulsy, G.M. (Eds.). Child and Family: Contexts for Development (French). Quebec City, Quebec: Les presses de l'Univerite Laval.

Straus, M.A. (1992). Children as witnesses to marital violence: A risk factor for lifelong problems among a nationally representative sample of American men and women. Report of the Twenty-Third Ross Roundtable. Columbus, OH: Ross Laboratories.

Straus, M.A., Gelles, R.J., \& Steinmetz, S.K. (1980). Behind closed doors. Garden City, NY: Anchor/Doubleday.

Straus, M.A. \& Gelles, R.J. (1990). Physical violence in American families. New Brunswick, NJ: Transaction Publishers.

Suh, E. \& Abel, E.M. (1990). The impact of spousal violence on the children of the abused. Journal of Independent Social Work, 4(4), 27-34.

Syers-McNairy, M. (1990). Women who leave violent relationships: Getting on with life. Unpublished doctoral dissertation. University of Minnesota, Minneapolis. 
Wallerstein, J.S. (1991). The long-term effects of divorce on children: A review. Journal of the American Academy of Child and Adolescent Psychiatry, 30, 349360.

Westra, B., \& Martin, H. P. (1981). Children of battered women. Maternal Child Nursing Journal, 10, 41-54.

Widom, C.S. (1989). The intergenerational transmission of violence. New York: Harry Frank Guggenheim Foundation.

Wolfe, D. A., Zak, L., Wilson, S., \& Jaffe, P. (1986). Child witnesses to violence between parents: Critical issues in behavioral and social adjustment. Journal of Abnormal Child Psychology, 14, 95-104.

Wolfe, D.A., Jaffe, P., Wilson, S.K. \& Zak, L. (1985). Children of battered women: The relation of child behavior to family violence and maternal stress. Journal of Consulting and Clinical Psychology, 53, 657-665.

Address for correspondence:

Jeffrey L. Edleson, PhD

School of Social Work

University of Minnesota

386 McNeal Hall

1985 Buford Avenue

St. Paul, Minnesota 55108-6142

USA

tel: $612-624-8795$

fax: 612-625-4288

email: magd@tc.umn.edu

Last updated on May 6, 1997

URL: / papers/witness.htm 